\title{
A METHODOLOGY FOR TSUNAMI HAZARD AND RISK ASSESSMENT: APPLICATION TO THE COASTAL AREA OF EL SALVADOR
}

\author{
Pino González-Riancho', Mauricio Gonzalez', Omar Gutiérrez'1, Oscar García-Aguilar', Iñigo \\ Aniel-Quiroga ${ }^{1}$, Ignacio Aguirre-Ayerbe ${ }^{1}$, Jose Antonio Álvarez ${ }^{2}$, Francisco Gavidia ${ }^{3}$, Ivonne \\ Jaimes $^{3}$, Jeniffer Larreynaga ${ }^{3}$
}

\begin{abstract}
Advances in the understanding and prediction of tsunami impacts allow the development of adaptation and mitigation strategies to reduce risk on coastal areas. This work, funded by the Spanish Agency for International Development Cooperation (AECID) during the period 2009-2012, presents a comprehensive methodology for tsunami risk assessment at any coastal area worldwide applied specifically in this case to the coast of El Salvador.
\end{abstract}

Keywords: tsunami risk assessment; hazard modeling; vulnerability; resilience; indicators; GIS; evacuation modeling.

\section{INTRODUCTION}

Tsunamis are relatively infrequent phenomena representing a greater threat than earthquakes, hurricanes and tornadoes, and causing the loss of thousands of human lives and extensive damage to coastal infrastructure around the world. Advances in the understanding and prediction of tsunami impacts allow the development of adaptation and mitigation strategies to reduce Risk on coastal areas. This work, funded by the Spanish Agency for International Development Cooperation (AECID) during the 2009-2012 period, presents a comprehensive methodology for assessing the risk of tsunamis on coastal areas worldwide applied specifically in this case to the coast of El Salvador. The study area is located in a high seismic activity area and has been hit by 11 tsunamis between 1859 and 1997, nine of which were recorded in the twentieth century and all of them having been generated by earthquakes.

This paper is structured as follows: the first chapter presents the Conceptual framework applied to this work, including the definition of risk components, dimension and scales, as well as the tools used; the second chapter shows the Tsunami Risk assessment including some example of results; and the third chapter presents the Tsunami Risk reduction approach together with a framework for tsunami evacuation planning. Finally some conclusions of the study are presented.

\section{CONCEPTUAL FRAMEWORK}

According to the Tyndall Centre (2003), the growing body of literature on vulnerability and adaptation contains a sometimes bewildering array of terms being the relationships between them often unclear, and applying different meanings to the same term when used in different contexts and by different authors. Besides the existing diverse definitions, researchers from the different disciplines focus on specific aspects of Risk.

Therefore, it is essential to first clarify the conceptual framework here proposed, which is based on a multidisciplinary and integrated approach aiming at providing a holistic picture of the possible impacts on the study area and consequently offering adequate risk reduction measures.

In order to carry out a proper tsunami risk assessment the concept of risk is here analyzed according to its components, dimensions and scales. Due to the complexity of this structure, a homogeneous way of expressing the results of the risk assessment is also proposed. The tools applied in this methodology are reviewed in further epigraphs.

\section{Risk components}

The conceptual framework of this methodology is based on the definition of Risk as the probability of harmful consequences or expected losses resulting from a given hazard to a given element at danger or peril over a specified time period (UNISDR 2004). Therefore, risk depends on the specific impact analyzed (e.g. loss of human lives), the probability of occurrence of the threat (e.g. flooding), the exposure of the studied elements (e.g. urban areas) and their vulnerability (sensitive groups and resilience). The risk components are described as follows (Figure 1).

\footnotetext{
${ }^{1}$ Environmental Hydraulics Institute "IH Cantabria". Universidad de Cantabria. C/Isabel Torres № 15. 39011 Santander. Spain

${ }_{2}^{2}$ National Geographic Institute. C/General Ibáñez Ibero, 3. 28003 Madrid, Spain

${ }^{3}$ Ministry of Environment and Natural Resources. Kilómetro 5 1 1/2 Carretera a Santa Tecla, Calle y Colonia Las Mercedes, Edificio MARN (anexo al edificio ISTA) No. 2, San Salvador. El Salvador.
} 


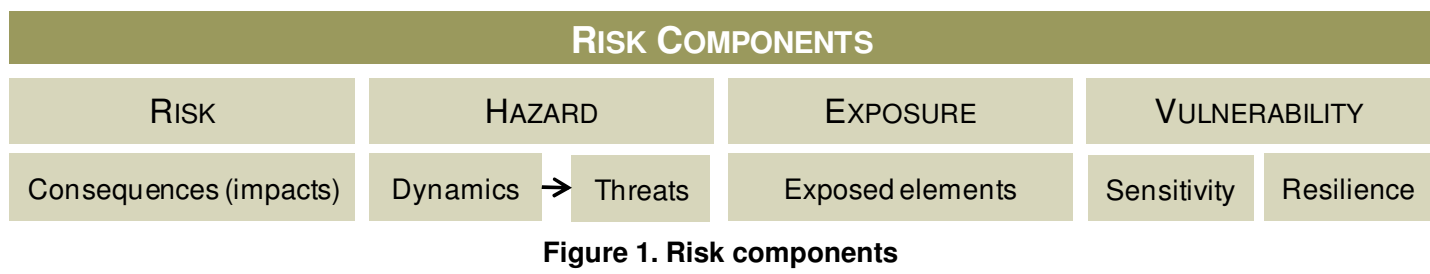

The definition of risk components is mainly based on those proposed by the UN International Strategy for Disaster Reduction (2004-2009) and implemented, among others, by the Intergovernmental Oceanographic Commission (IOC-UNESCO 2009) in the document "Hazard Awareness and Risk Mitigation in Integrated Coastal Area Management (ICAM)"

- Risk: the probability of harmful consequences or expected losses (deaths, injuries, property, livelihoods, economic activity disrupted or environment damaged) resulting from interactions between natural or human-induced hazards and vulnerable conditions (UNISDR 2004). Risk is a combination of the consequences of an event (hazard) and the associated likelihood/probability of its occurrence (ISO 31010).

- Consequences/Impacts: the negative effects of disaster expressed in terms of human, economic, environmental and political / social impacts (ISO 31010)

- Hazard: is a dangerous phenomenon, substance, human activity or condition that may cause loss of life, injury or other health impacts, property damage, loss of livelihoods and services, social and economic disruption, or environmental damage (UNISDR 2009).

- Dynamics: variables and physical processes capable of generating a threat

- Threat: the potentially damaging physical event, phenomenon or human activity that may cause negative consequences. It is here understood as the specific hazard aspects being studied (e.g. when analyzing the hazard climate change the threats could be the sea level rise, the increase of tropical cyclones, droughts, etc.), which are characterized by their location, intensity, duration, frequency and probability.

- Exposure: People, property, systems, or other elements present in hazard zones that are thereby subject to potential losses (UNISDR 2009)

- Vulnerability: the conditions determined by physical, social, economic and environmental factors or processes, which increase the susceptibility of an exposed community to the impact of hazards (adapted from UNISDR 2004). In probabilistic/quantitative risk assessments the term vulnerability expresses the part or percentage of Exposure that is likely to be lost due to a certain hazard (EC 2010).

- Sensitivity: predisposition to be affected by physical or socio-economic changes, including damage and losses (UNISDR 2004). It is here understood as an intrinsic quality of the exposed element.

- Resilience: The ability of a system, community or society exposed to hazards to resist, absorb, accommodate to and recover from the effects of a hazard in a timely and efficient manner, including through the preservation and restoration of its essential basic structures and functions. (UNISDR 2009)

\section{Risk dimensions}

The coast is a complex system where the marine dynamics, the coastal ecosystems and the human activities converge. Understanding the interrelationships between (i) human societies and their behavior patterns, (ii) coastal resources and their uses, (iii) coastal risks, and (iv) policies and institutions that govern human activities is essential for an adequate coastal management. An integrated and multidisciplinary approach is important to analyze the entire system instead of only considering specific aspects of a single sector or scientific discipline, being therefore possible to understand the interrelationships that control the behavior and equilibrium of the coastal system.

The analysis of the scientific information coming from different disciplines is usually very complex. The aforementioned integrated approach is necessary from the earliest planning stages of the study, since it will facilitate the effective consideration and integration of the variables controlling the behavior of complex systems.

This statement is applied here throughout the exposure and vulnerability assessment as they are decomposed to incorporate different coastal dimensions. The methodology assesses the degree of 
vulnerability in each dimension using the appropriate units, being this quantification the starting point to subsequent evaluations to determine if the proposed risk reduction measures are effective and if the vulnerability is or is not reduced.

For a tsunami risk assessment the human, environmental, socioeconomic and infrastructures dimensions should be analyzed (Figure 2).

\begin{tabular}{|c|c|c|c|}
\hline \multicolumn{3}{|c|}{ RISK DIMENSIONS } \\
\hline HUMAN & ENVIRONMENTAL & SOCIOECONOMIC & INFRASTRUCTURES \\
DIMENSION & DIMENSION & DIMENSION & DIMENSION \\
\hline
\end{tabular}

Figure 2. Risk dimensions

\section{Risk scales}

The elements at risk vary with time and space, as both factors will change the amount and type of exposed and vulnerable elements. For this reason, and according to EC (2010), impact assessments need to define a reference space-time window.

This methodology proposes applying different spatial and temporal scales for risk calculation (Figure 3). The anticipated scales are as follows:

- Spatial scale. Risk assessments at both national and local levels are here proposed. The first one aims at having an overview of the possible impacts on the different dimensions, permitting the comparison between dimensions and between municipalities. The second one aims at performing a detailed analysis of the areas which are most at risk.

- Temporal scale. The time scale in this methodology aims to understand the human and environmental behaviors and patterns.

\begin{tabular}{|c|c|c|c|}
\hline \multicolumn{2}{c}{ RISK SCALES } \\
\hline \multicolumn{2}{|c|}{ SPATIAL SCALE } & & TEMPORAL SCALE \\
\hline National & Local & Annual & Temporal \\
\hline
\end{tabular}

Figure 3. Risk scales

Considering all the above-mentioned approach, a general Tsunami Risk Assessment is proposed to be organized according to the structure shown in Figure 4:

\begin{tabular}{|c|c|c|c|c|c|c|c|c|}
\hline \multicolumn{3}{|c|}{ RISK } & \multicolumn{3}{|c|}{ HAZARD } & EXPOSURE & \multicolumn{2}{|c|}{ VULNERABILITY } \\
\hline CONSEQUENCES & $\begin{array}{l}\text { TIME } \\
\text { SCALE }\end{array}$ & $\begin{array}{l}\text { SPATIAL } \\
\text { SCALE }\end{array}$ & ProbabILITY & Dynamics & THREAT & $\begin{array}{l}\text { EXPOSED } \\
\text { ELEMENTS }\end{array}$ & Sensitivity & RESILIENCE \\
\hline Human impacts & \multirow{4}{*}{$\begin{array}{l}\text { Annual } \\
\text { Seasonal } \\
\text { Weekly } \\
\text { Daily }\end{array}$} & \multirow{4}{*}{$\begin{array}{c}\text { National } \\
\text { Regional } \\
\text { Local }\end{array}$} & \multirow{4}{*}{$\begin{array}{l}\text { Deterministic } \\
\text { analysis } \\
\text { Probabilistic } \\
\text { analysis } \\
\text { (return periods) }\end{array}$} & \multirow{4}{*}{$\begin{array}{c}\text { Tsunamigenic } \\
\text { sources } \\
\text { Sea level } \\
\text { Tsunami } \\
\text { waves } \\
\text { Tides }\end{array}$} & \multirow{4}{*}{$\begin{array}{c}\text { Flooding } \\
\text { Wave } \\
\text { velocity }\end{array}$} & $\begin{array}{l}\text { Human } \\
\text { exposure }\end{array}$ & $\begin{array}{c}\text { Human } \\
\text { sensitivity }\end{array}$ & \multirow{4}{*}{$\begin{array}{c}\text { Information and } \\
\text { awareness } \\
\text { Warning and } \\
\text { evacuation } \\
\text { Emergency } \\
\text { response }\end{array}$} \\
\hline Environmental impacts & & & & & & $\begin{array}{l}\text { Environmental } \\
\text { exposure }\end{array}$ & $\begin{array}{l}\text { Environmental } \\
\text { sensitivity }\end{array}$ & \\
\hline Socioeconomic impacts & & & & & & $\begin{array}{l}\text { Socioeconomic } \\
\text { exposure }\end{array}$ & $\begin{array}{l}\text { Socioeconomic } \\
\text { sensitivity }\end{array}$ & \\
\hline Infrastructures impacts & & & & & & $\begin{array}{l}\text { Inf rastructures } \\
\text { exposure }\end{array}$ & $\begin{array}{l}\text { Inf rastructures } \\
\text { sensitivity }\end{array}$ & \\
\hline
\end{tabular}

Figure 4. Structure of the Tsunami Risk Assessment

The Risk Assessment and Mapping Guidelines for Disaster Management (EC 2010) suggests having the available impacts analyzed separately for the different dimensions, although they may be combined or aggregated for certain purposes. Therefore, this framework combining different risk components and dimensions proposes also two types of results (Figure 5):

- Partial results (separately for each component and dimension)

- Aggregated results (combining all dimensions). 


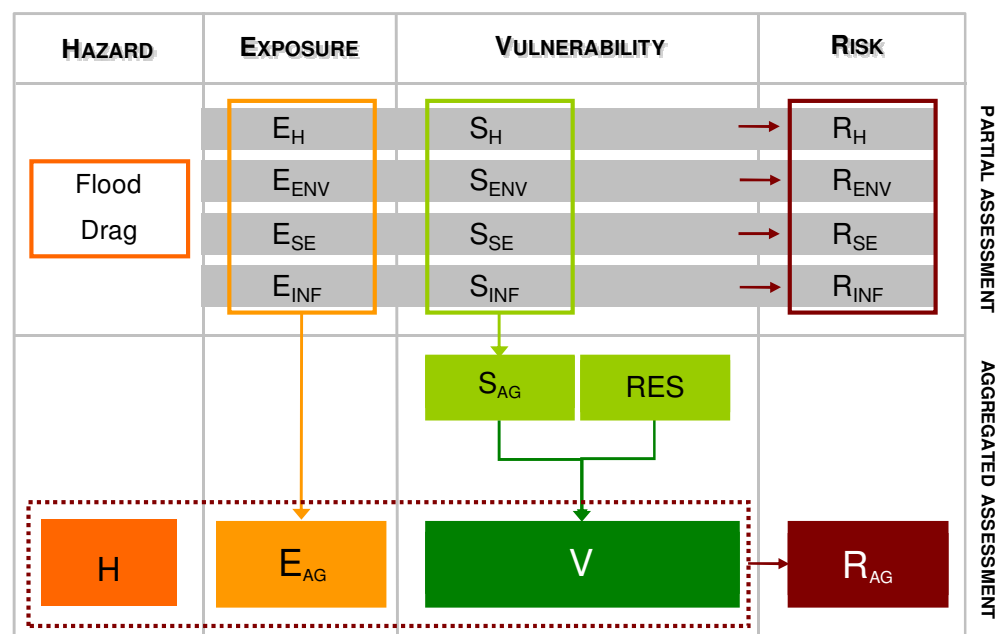

Figure 5. Risk results: partial and aggregated results

The application of this general framework to the case study of El Salvador is as follows:

- The Human, Environmental, Socioeconomic and Infrastructures dimensions are considered. Therefore the risk of having impacts in these four dimensions is analyzed.

- The spatial scale considers the national and local level. As the planning unit is the municipality, the national level includes the 29 coastal municipalities while the local scale focuses on five municipalities: Acajutla, La Libertad and those composing Jiquilisco Bay (Jiquilisco, Puerto El Triunfo and San Dionisio).

- The time scale considers (i) the population movements due to holiday patterns (rainy season / dry season, weekday / weekend) in the human system, both at the national and local scales; and (ii) the migration patterns or breeding / nesting periods for the environmental system at the local level.

- The hazard assessment is carried out through the deterministic analysis to understand the possible worst case scenario.

- The threats analyzed are the flooding (water depth) at the national level and the drag (depth and water velocity) at the local level.

\section{Risk tools}

A brief description of the main tools applied in this methodology is provided:

- Hazard Modeling. The hazard assessment is based on the numerical modeling of the dynamics at study (tsunamigenic sources, tsunami waves, sea level, etc.) to understand the probability, frequency, intensity, and duration of a hypothetical event as well as the potentially affected area.

- Indicators. A set of indicators and indices has been developed to measure the exposure and sensitivity of the coastal dimensions as well as the resilience of the society and communities at risk.

- Geographic Information System. A GIS allows storing, managing and analyzing the data and information concerning the study zone, including vector and raster datasets of the physical characteristics of the coast as well as of societies, economy and infrastructure. It aims at supporting every decision with geo-referenced information. The combination of partial maps related to each dimension generates the aggregated map. It has also been extremely useful for the evacuation planning and modeling.

\section{TSUNAMI RISK ASSESSMENT}

\section{Hazard Assessment}

The hazard assessment (Phase I of the project) is based on propagation models for earthquakegenerated tsunamis, developed through the characterization of tsunamigenic sources -sismotectonic faults- and other dynamics (waves, sea level, etc.). Simulations of historical and potential tsunamis with greater or lesser affection to the country's coast have been performed - as shown in figure 6- including distant sources (distances greater than $2000 \mathrm{~km}$ to the coast and tsunami travel times greater than 4 hours), intermediate (between 700 and $2000 \mathrm{~km}$ and tsunami travel times between 1 and 4 hours) and close (located in the subduction trench off the country's coast and travel times of less than one hour). 

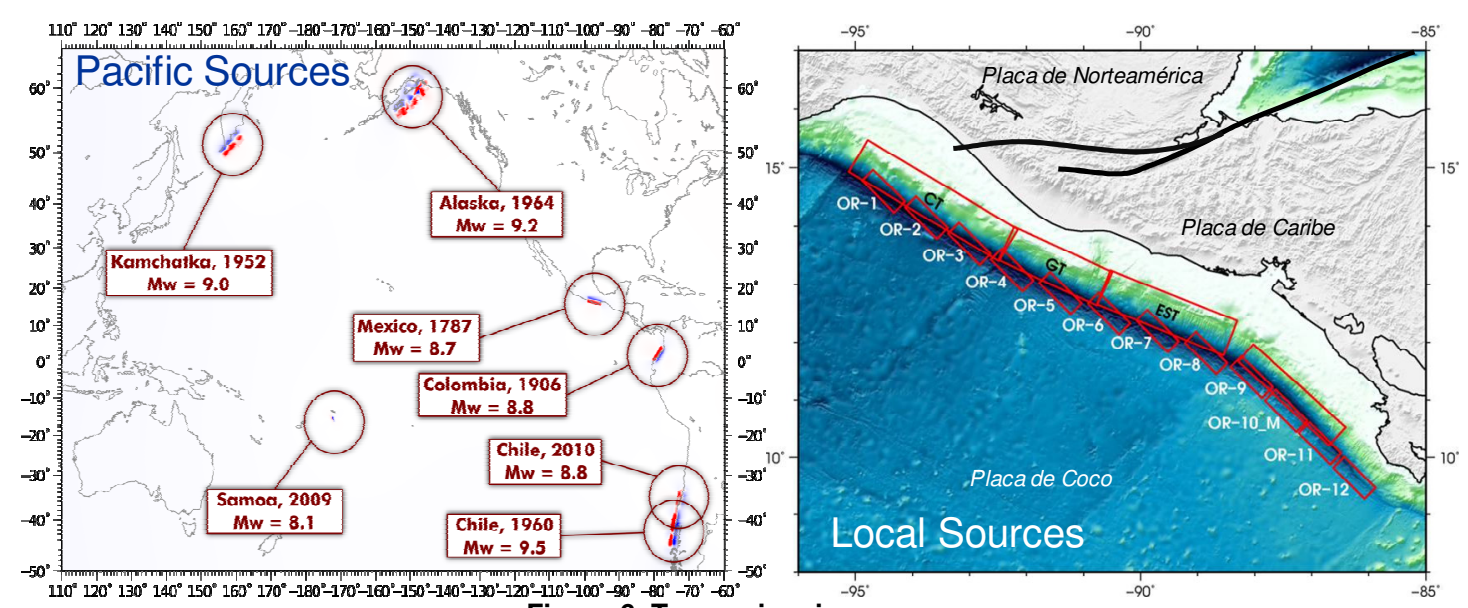

Figure 6. Tsunamigenic sources

The numerical propagations have been simulated using the $\mathrm{C} 3$ model (Olabarrieta et al, 2008). This model was developed by IH Cantabria and it combines two models: COMCOT and Tsunami-Claw in order to solve Nonlinear Shallow water equations (NSWE). C3 is a finite differences numerical model validated and applied to several historical tsunami events such as the 1960 Chilean tsunami (Liu et al. 1994), the 1992 Flores Islands (Indonesia) tsunami (Liu et al. 1995), the 2004 Indian Ocean tsunami (Wang and Liu, 2005) and the Algerian tsunami 2003 (Wang and Liu, 2005). Additionally, the model has been validated using the benchmark cases proposed within the framework of the European Tsunami Project TRANSFER. (http://www.transferproject.eu). C3 is especially designed to simulate tsunami events. The parameters of the earthquake can be introduced via the Okada fault model. Then the model solves the NSWE using a gridded domain, and, finally it provides several data, such as free surface elevation on every point in the grid or temporal series of velocity and total depth at each point. In this case 4 levels of nested grids have been used in order to get a cell size of 30 meters on the coast of El Salvador.

A deterministic analysis (aggregated analysis that combines the 23 worst credible cases of tsunamis that could impact on the Salvadoran coast) has been carried out, being the main output different hazard maps (maximum wave height elevation, maximum water depth, minimum tsunami arrival time, maximum flooding level or "Run-up", hazard degree for people based on incipient velocity for people instability) along the coast of El Salvador and at some relevant locations (high resolution analysis). See figures 7,8 and 9 .

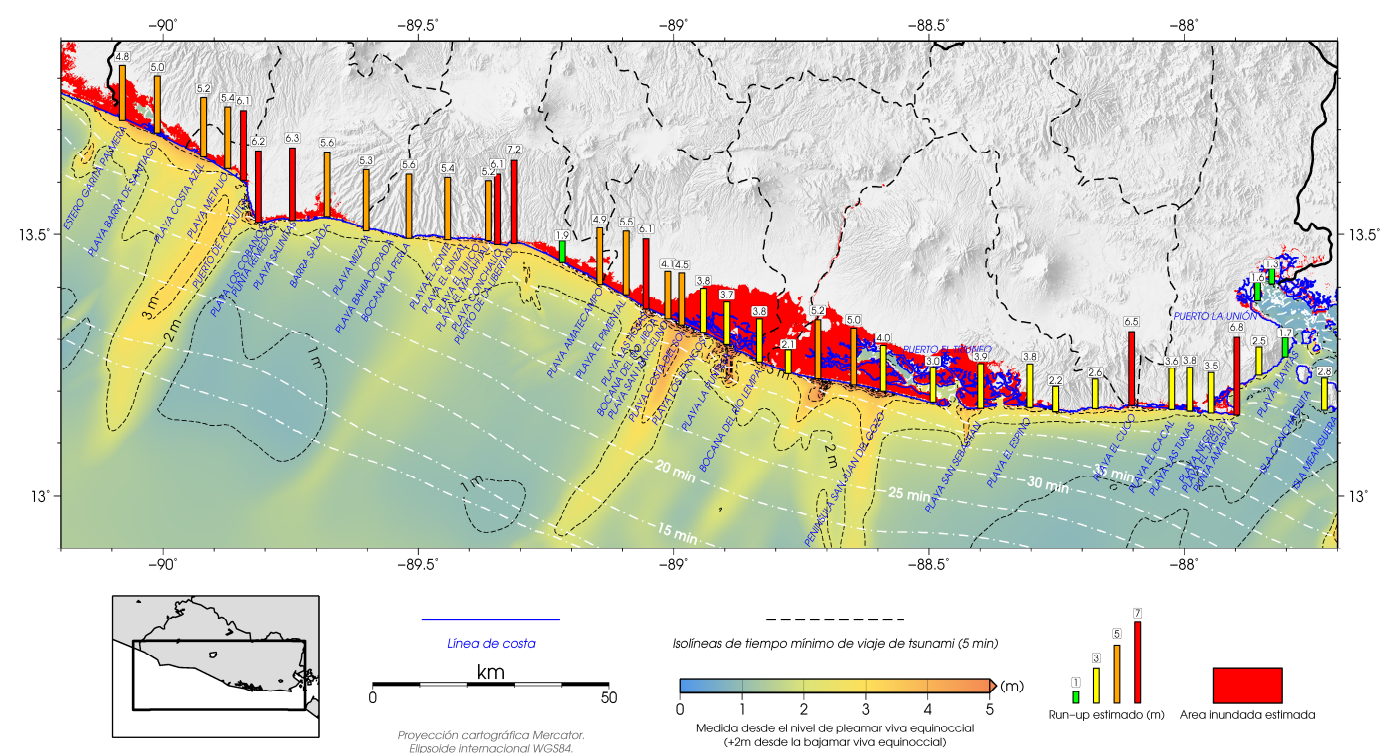

Figure 7. Tsunami Hazard Map - El Salvador (global map). Maximum total water depth (m), maximum Run-up $(\mathrm{m})$, estimated flooded area and minimum tsunami arrival time $(\mathrm{min})$. Aggregated map combining the worst scenarios of distant, intermediate and close tsunamigenic sources. 


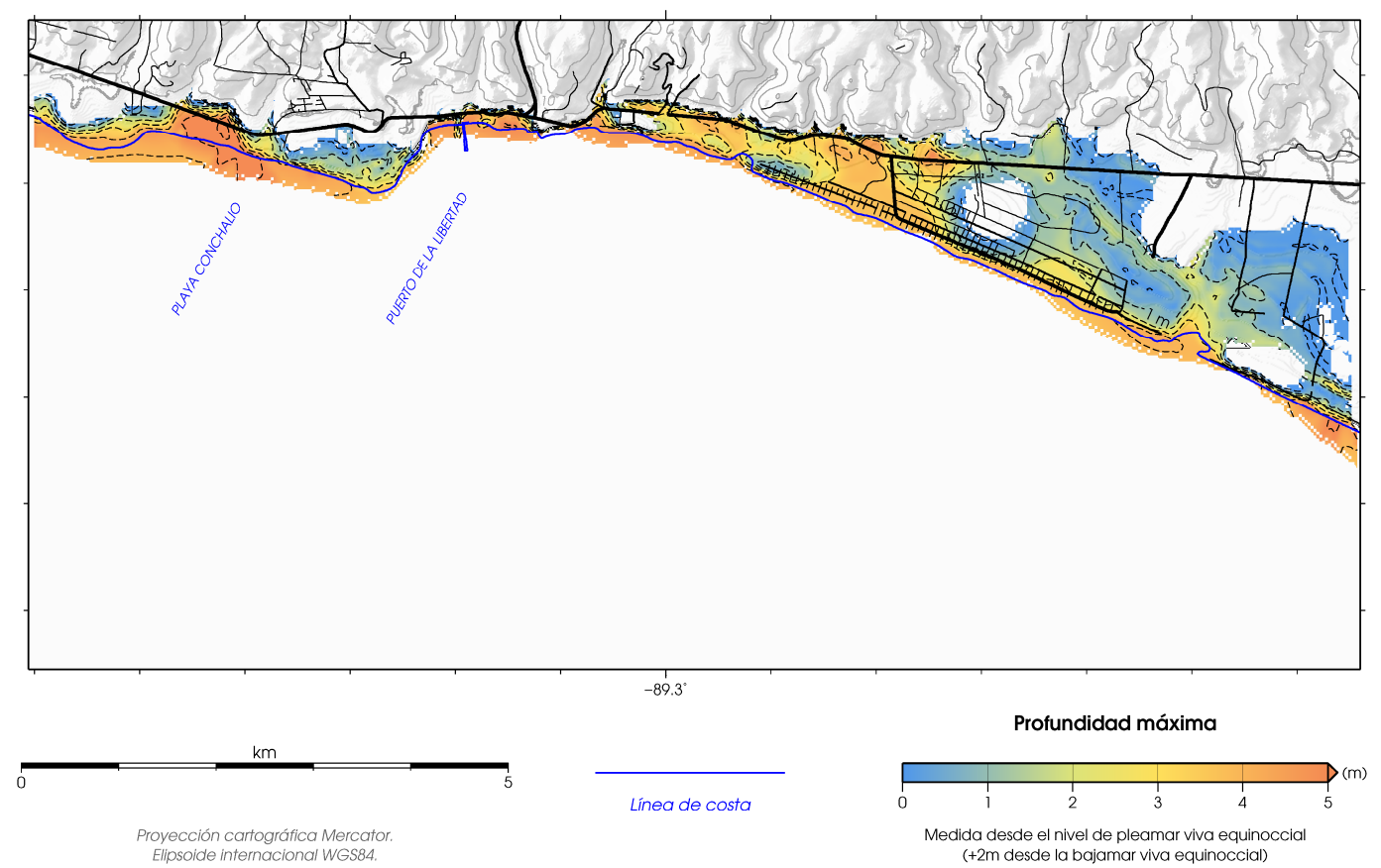

Figure 8. Flooding Local Map - La Libertad Area (zone with highest Hazard: run-up=7.2m). Maximum Total Water Depth (m). Aggregated map combining the worst scenarios of distant, intermediate and close tsunamigenic sources.

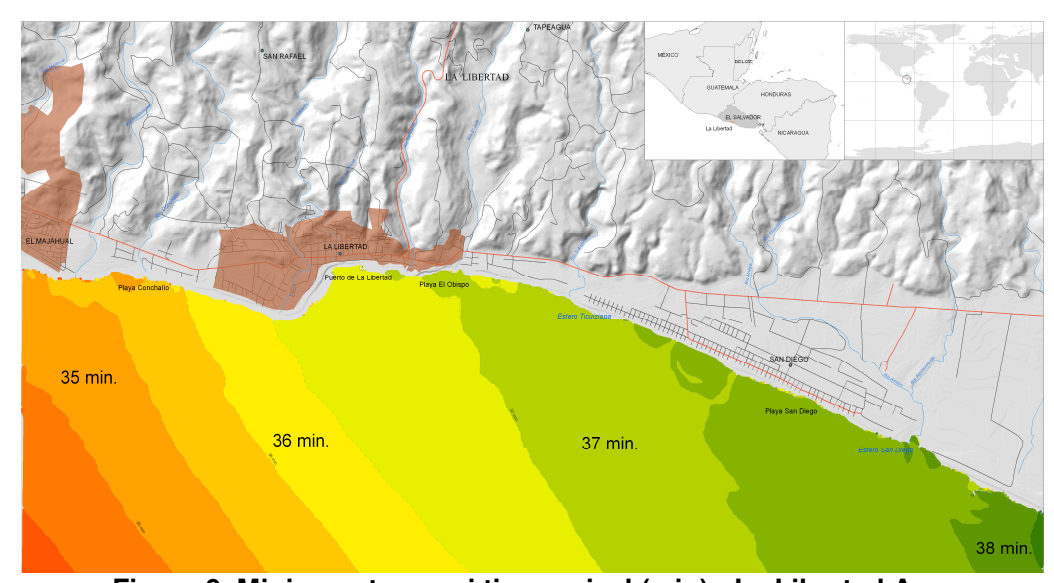

Figure 9. Minimum tsunami time arrival (min) - La Libertad Area

\section{Vulnerability Assessment}

The Vulnerability assessment of the identified exposed elements (Phase II of the project) is based on an integrated approach to understand the interrelationships between the different coastal dimensions, and composed of the Sensitivity and Resilience assessments.

Sensitivity Assessment. A set of indices and indicators have been developed (Figure 10) to assess the sensitivity of each dimension to a tsunami event. Several mathematical-statistical procedures have also been applied-i.e. standardization, weighting, thresholds and classification-. This set is supported by a Geographic Information System (GIS) that allows graphical representation of physical, environmental, social, economic and infrastructure characteristics of the coast. The set of indicators is adapted to different spatial and temporal scales: the spatial scale includes both national and local levels while the time scale considers the movements caused by holiday patterns in the human population and migration patterns and breeding/nesting seasons in the environmental system.

It is important to point out the analytical soundness of all the indicators, the independence among them and the relevance of the measured phenomenon. The robustness, sensitivity and transparency of the indicator system allow managing the information at the indices level as well as decomposing them into the different indicators and working directly with the base data. 


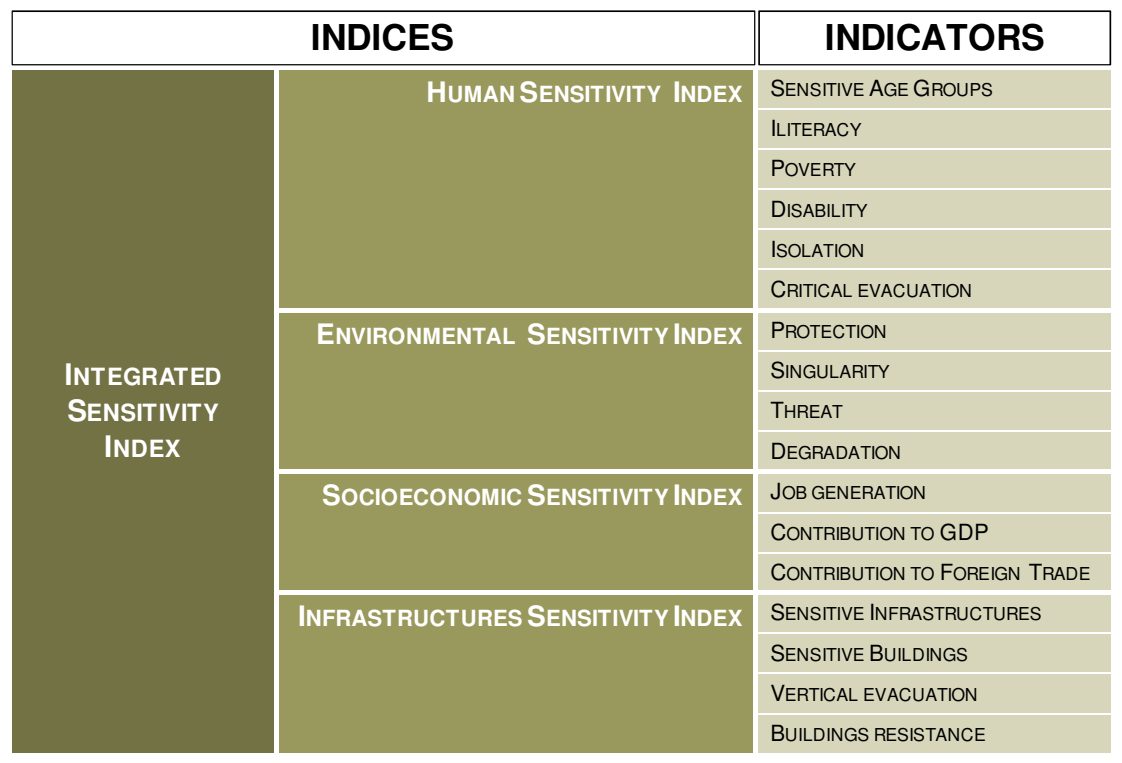

Figure 10. Sensitivity indicators

An example of Sensitivity partial results for the coast of El Salvador is shown in Figure 11, where the sensitivities of each dimension are mapped. It can be clearly seen that the most sensitive areas in the case of a possible tsunami event vary according to the dimension being analyzed. This example proves how for the Human Dimension: the most active and populated municipalities are emphasized; for the Environmental Dimension: those belonging to Jiquilisco Bay and La Union Bay due to the existence of large areas of mangrove which are extremely relevant in terms of biodiversity and ecosystem services to the community, as well as to the existence of some endangered species such as the Spider Monkey, several species of sea turtles (Carey, Baule, Prieta, Black turtle) and crocodiles; for the Socioeconomic Dimension: those municipalities with more developed tourism, agricultural, industrial and port activities are highlighted; finally, for the Infrastructures Dimension: those municipalities having the most relevant industrial, commercial and fishing ports in the country have resulted more sensitive.
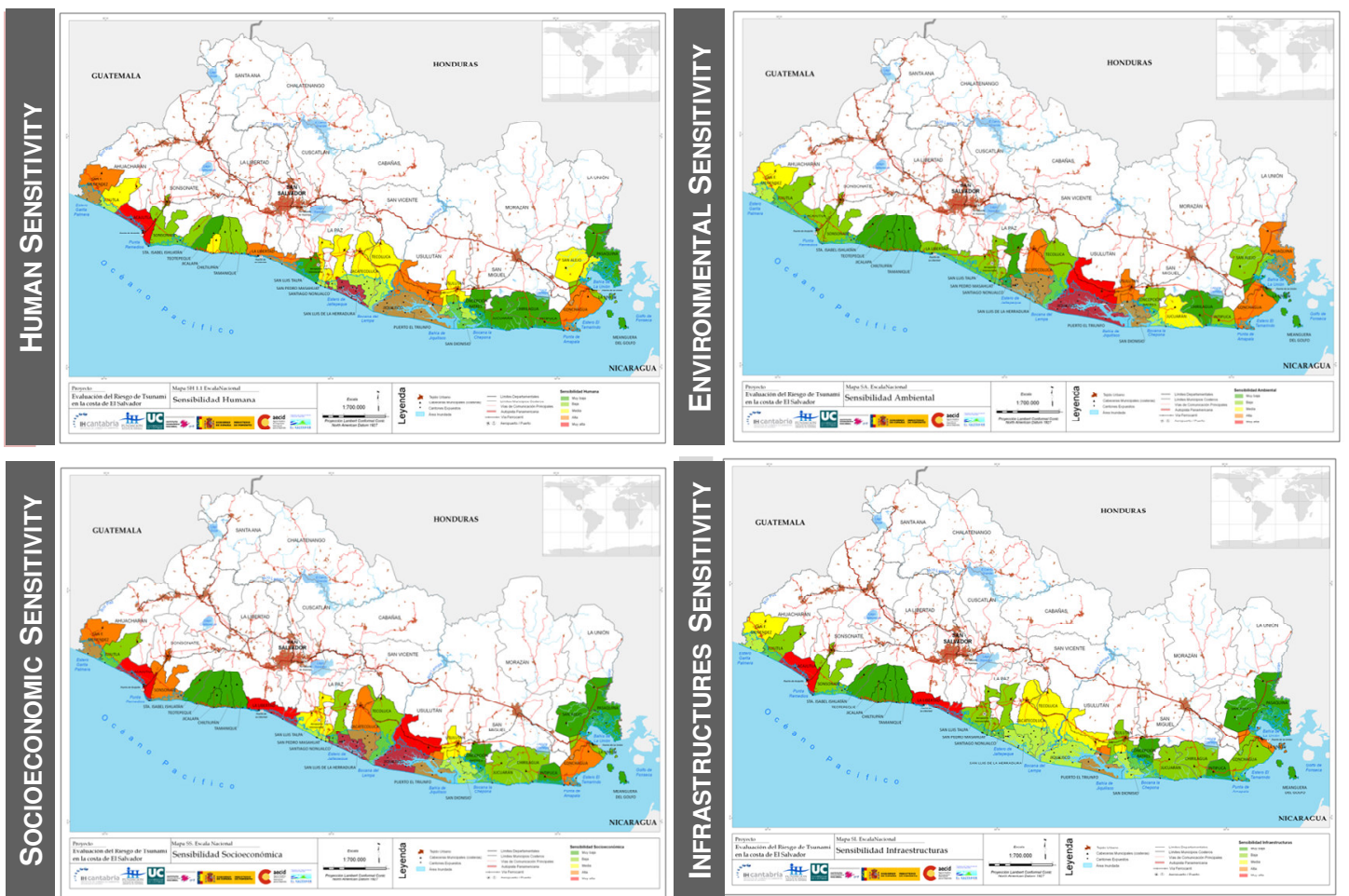

Figure 11. Partial results: Sensitivity of each dimension for El Salvador coastal area 
Graphs in Figure 12 present the indicators obtained for each dimension.
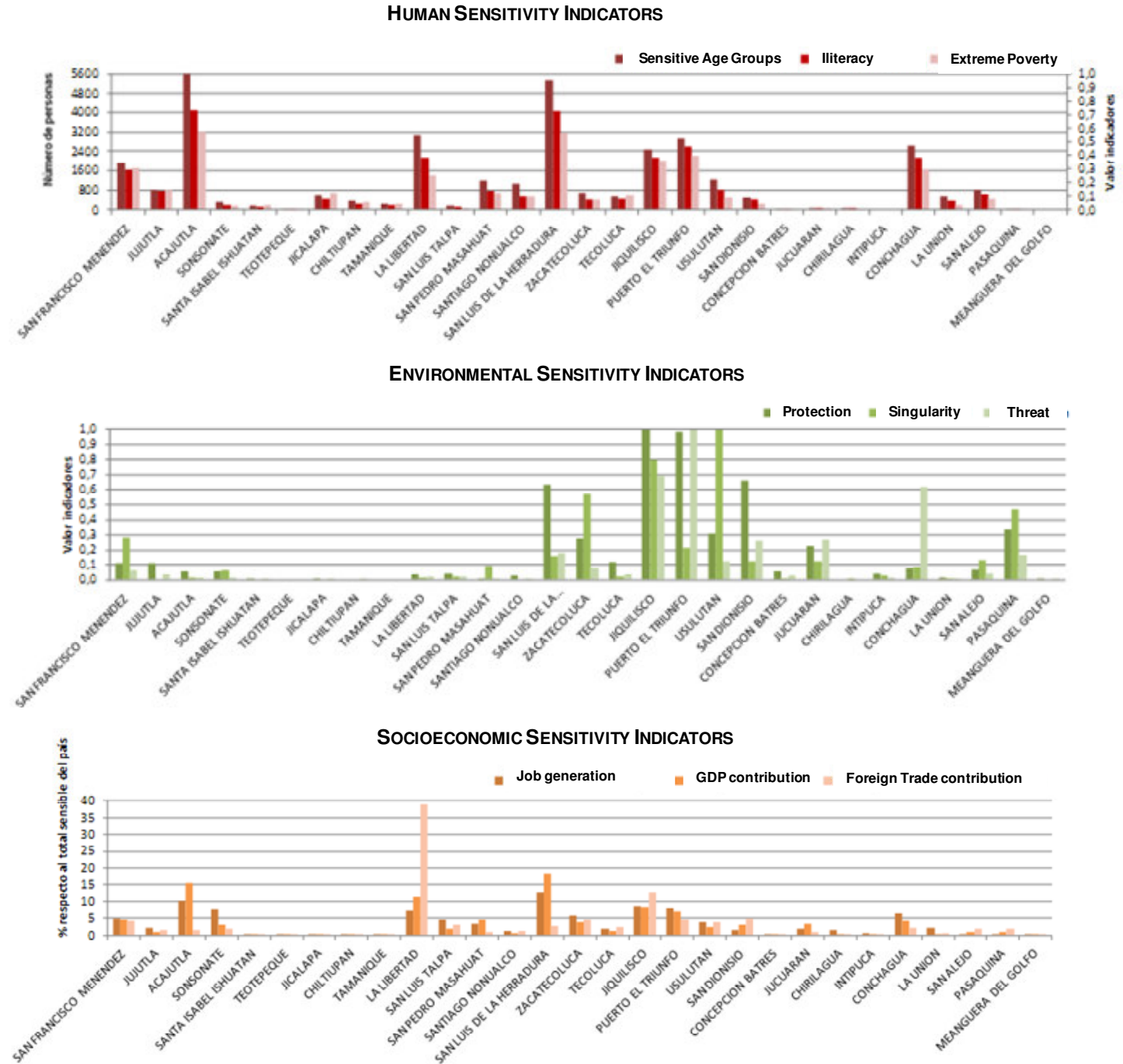

INFRASTRUCURES SENSITIVITY INDICATORS

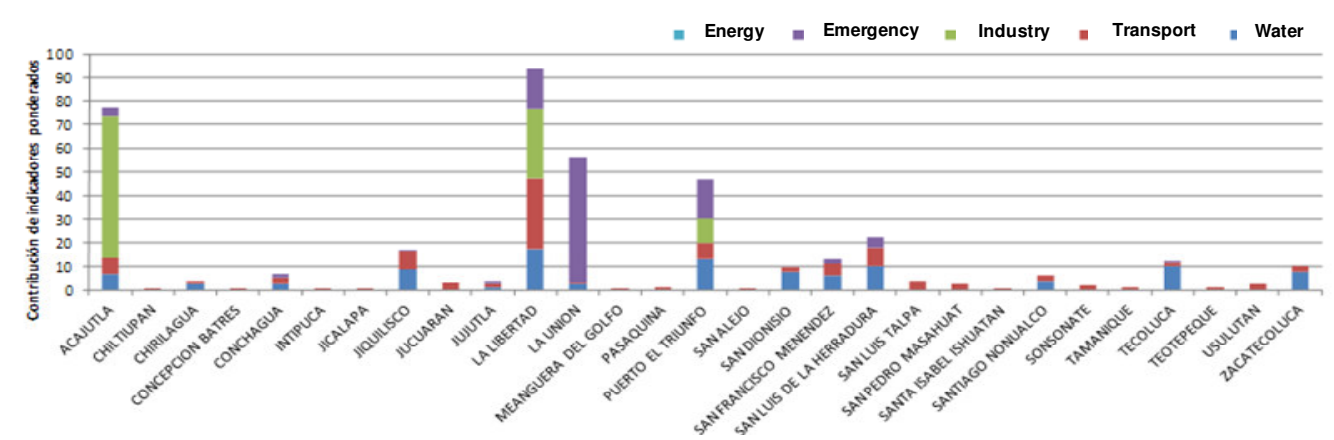

Figure 12. Example of Indicators obtained for each dimension

Resilience Assessment. Resilience is the capacity of a system to absorb disturbance and reorganize while undergoing change so as to still retain essentially the same function, structure, identity, and feedbacks (Walker et al. 2004), therefore it is here proposed to be analyzed through two of society's capacities one related to the pre and during-event, and the second one to the post-event: 
- Coping capacity: the means by which people or organizations use available resources and abilities to face adverse consequences that could lead to a disaster (UNISDR 2004)

- Recovery capacity: the ability of the system to recover following a disaster.

To evaluate the resilience and its Coping and Recovery Capacities, this methodology proposes analyzing the four phases of emergency management: Information and Awareness, Warning and Evacuation, Emergency Response and Disaster Recovery. Figure 13 shows the relationship between the elements of resilience and the phases of emergency management. Data collection for the construction of the Resilience Index is carried out through a short questionnaire which identifies the degree of organization and response within a community in case of an emergency. The questionnaire has been answered by the person responsible for the Municipal Civil Protection Committees (CPCM), at least one non-governmental organization with a greater presence in the area and three community leaders from different localities.

\begin{tabular}{l|c|l} 
& $\begin{array}{c}\text { INFORMATION } \\
\text { ANDAWARENESS }\end{array}$ & $\begin{array}{l}\text { Leadership and community members are aware of hazards and risk information is } \\
\text { utilized when making decisions. }\end{array}$ \\
$\begin{array}{l}\text { COPING } \\
\text { CAPACITY }\end{array}$ & $\begin{array}{c}\text { WARNING AND } \\
\text { EVACUATION }\end{array}$ & $\begin{array}{l}\text { Community is capable of receiving notifications and alerts of coastal hazards, } \\
\text { warning at-risk populations, and individuals acting on the alert. }\end{array}$ \\
\cline { 2 - 3 } & $\begin{array}{l}\text { EMERGENCY } \\
\text { RESPONSE }\end{array}$ & $\begin{array}{l}\text { Mechanisms and networks are established and maintained to respond quickly to } \\
\text { coastal disasters and address emergency needs at the community level. }\end{array}$ \\
\hline $\begin{array}{l}\text { RECOVERY } \\
\text { CAPACITY }\end{array}$ & $\begin{array}{c}\text { DISASTER } \\
\text { RECOVERY }\end{array}$ & $\begin{array}{l}\text { Plans are in place prior to hazard events that accelerate disaster recovery, engage } \\
\text { communities in the recovery process, and minimize negative environmental, social, } \\
\text { and economic impacts. }\end{array}$
\end{tabular}

Figure 13. Resilience elements and related Emergency Phases

Figure 14 shows the results of Resilience Index at the national level, which is based on two indicators, the coping and recovery capacity of each municipality, represented by the grey bars in the map. These results allow understanding the main weaknesses in emergency management and proposing site-specific corrective measures.

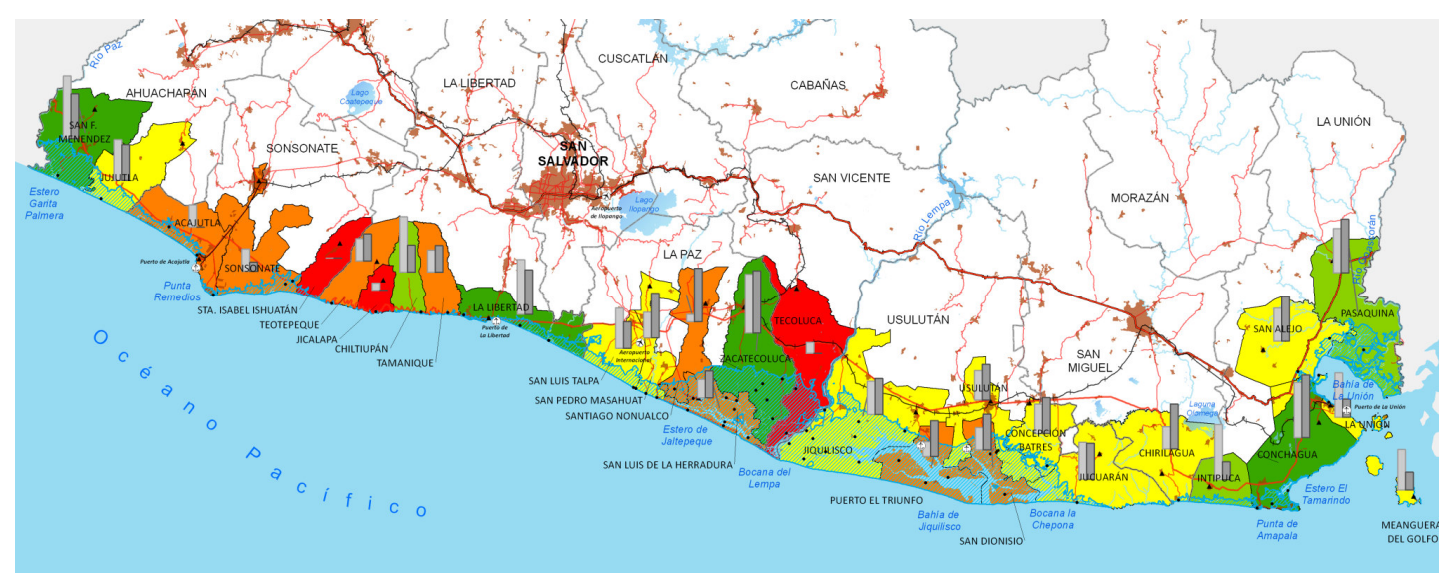

Figure 14 Resilience Index map for El Salvador coastal area

\section{Risk Assessment}

A final global Risk assessment (hazard, exposure and vulnerability analyses for every dimension and both temporal and spatial scales) allows identifying critical areas regarding sensitivity hot spots or resilience weaknesses, providing essential information for the formulation of a set of risk reduction measures.

The main advantage of this methodology is the generation of partial and aggregated results, as well as the possibility of disaggregating them again into risk components, dimensions and indicators in order to understand the precise reason of a high risk result for example. This is extremely important for proposing adequate risk reduction measures. 


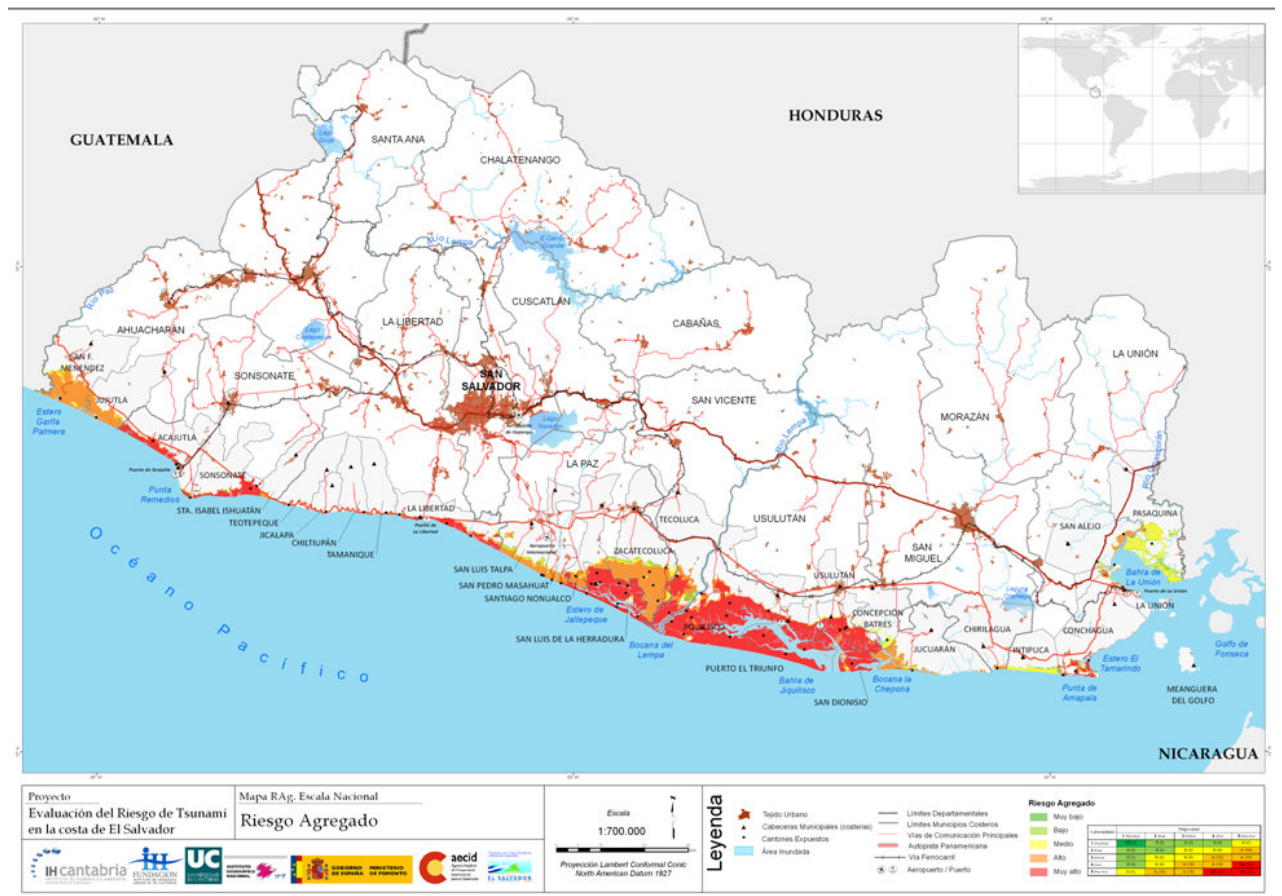

Figure 15. Aggregated Risk map for El Salvador coastal area

\section{TSUNAMI RISK REDUCTION}

The risk assessment carried out helps identify the appropriate risk reduction measures according to the definition of Disaster Risk Reduction (UNISDR, 2009b) as the concept and practice of reducing disaster risks through systematic efforts to analyze and manage the causal factors of disasters, including through reduced exposure to hazards, lessened vulnerability of people and property, wise management of land and the environment, and improved preparedness for adverse events.

Risk Reduction Measures can be of two types:

- Adaptation measures: adjustment in natural or human systems in response to actual or expected stimuli and their effects, which moderates harm or exploits to receive beneficial opportunities (IPCC, 2001).

- Mitigation Measures: structural and nonstructural measures taken to limit the adverse impact of natural hazards (UNISDR, 2004).

Therefore, it is here understood that Mitigation Measures aim to reduce the threat while Adaptation Measures basically aim to reduce the vulnerability (through reducing the sensitivity or increasing the resilience).

Different adaptation and mitigation measures have been proposed for the coastal area of El Salvador, based on the results of the Risk assessment. This paper focuses on the tsunami evacuation planning.

\section{Tsunami Evacuation Planning}

One of the main outputs of a tsunami risk assessment is the design of an evacuation plan, being obviously a requirement for tsunami risk reduction. The methodology presented here provides the needed information for evacuation planning.

Figure 16 shows the methodological framework proposed for Evacuation planning. The combination of the Population Evacuation Index (PEI), the Evacuation Routes Index (ERI) and the Safe Areas Index (SAI) is the essential information for preparing a Preliminary Evacuation Proposal that distributes the population among the different shelters. The Evacuation Time of the population is modeled combining the evacuation distances and speeds obtained from the Preliminary evacuation Proposal and the warning time obtained from the Tsunami arrival time and the existing warning protocols. This permits identifying Critical areas that won't be able to evacuate and which will be the main objective of the Risk reduction measures proposed. All this information will feed the Final Evacuation Plan for the municipality. Figure 17 shows an example of evacuation area in the coastal zone of La Libertad. 


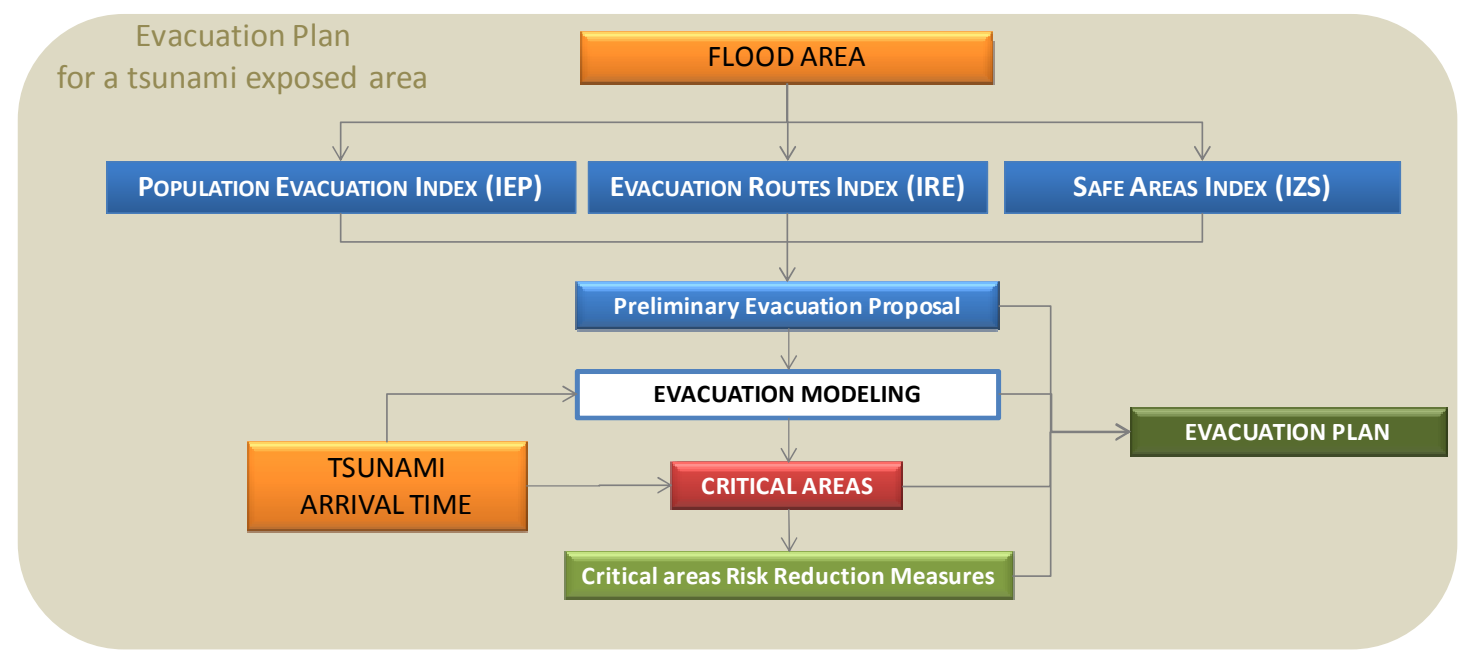

Figure 16. Evacuation Planning Framework

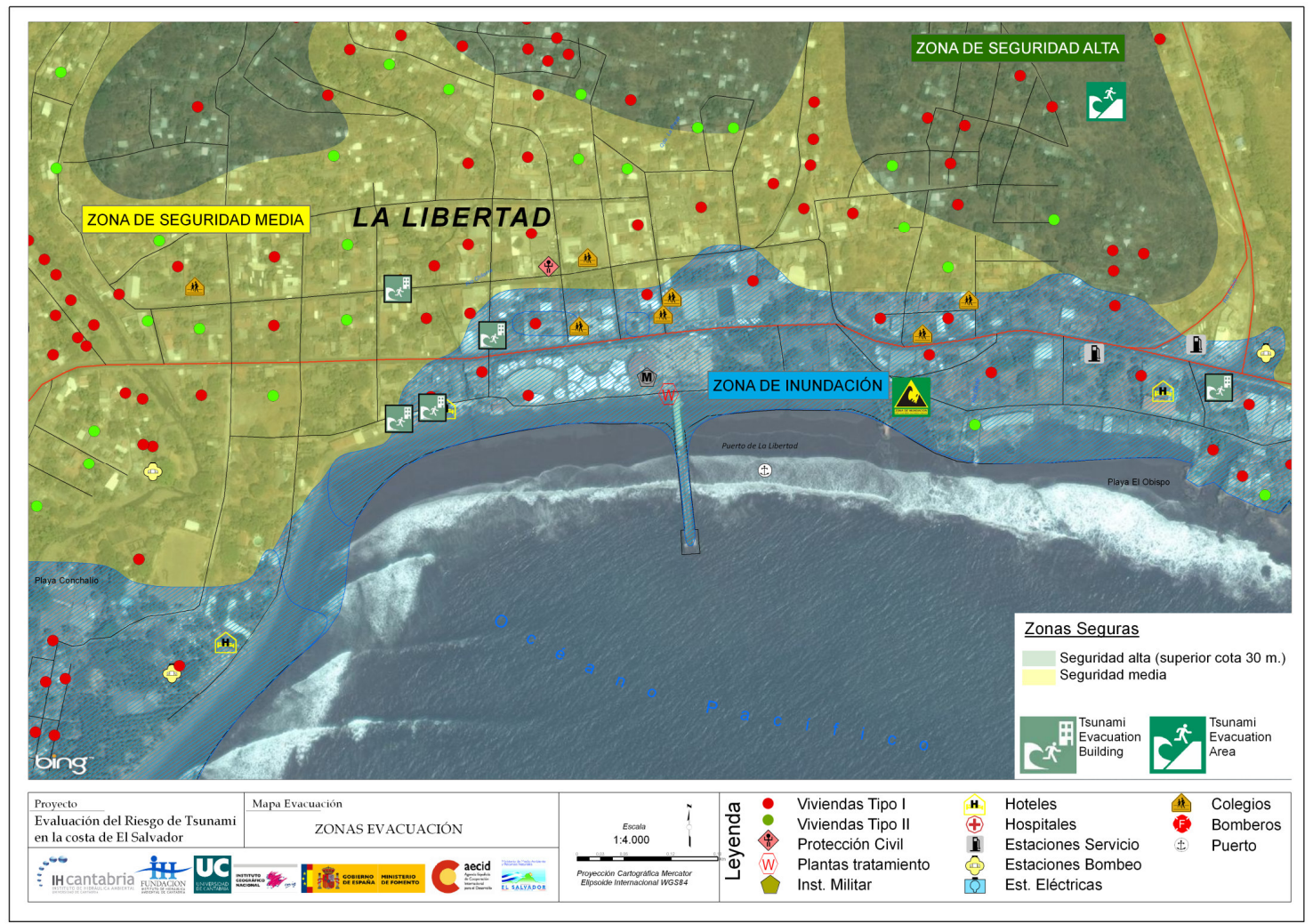

Figure 17. Evacuation areas in La Libertad area (colored areas: flooded area in blue, intermediate security areas in yellow, high security areas in green. colored dots: buildings materials).

\section{CONCLUSIONS}

Advances in the understanding and prediction of tsunami impacts allow the development of adaptation and mitigation strategies to reduce risk on coastal areas.

An Integrated Methodology for Tsunami Risk Assessment has been proposed. This methodology can be applied to any coastal area and a pilot case for the coastal are of El Salvador is shown in this paper. The methodology includes hazard modeling and vulnerability indicators covering different coastal dimensions. Coastal specificity is fulfilled through different spatial scales 
while different temporal scales permit a long-term planning approach. Partial and aggregated results are provided (risk of each dimension and aggregated risk).

This methodology provides essential information for Tsunami Risk Reduction as it has been designed from the very beginning for this purpose. It permits identifying ways to reduce the sensitivity of each dimension and to increase the resilience of communities.

A specific methodology for Tsunami Evacuation Planning has also been incorporated, which is based on evacuation indexes, evacuation modeling to identify critical areas, and a framework for the development of an evacuation plan.

\section{ACKNOWLEDGMENTS}

We would like to thank the Spanish Agency for International Development Cooperation (AECID) for supporting this research project and our fruitful collaboration Spain-El Salvador.

\section{REFERENCES}

Álvarez Gómez, J. A. 2009. Tectónica Activa y Geodinámica en el Norte de Centroamérica. Ph.D. thesis, Universidad Complutense de Madrid, Madrid.

Álvarez Gómez, J. A. Meijer, P. T., Martínez-Díaz, J. J., \& Capote, R., 2008. Constraints from finite element modeling on the active tectonics of northern Central America and the Middle America Trench. Tectonics, 27.

European Commission, 2010. Risk Assessment and Mapping Guidelines for Disaster Management. Staff Working Paper SEC(2010) 1626 final. Brussels, 21.12.2010

Jenks, George F. 1967. "The Data Model Concept in Statistical Mapping", International Yearbook of Cartography 7: 186-190.

Jonkman S. N. Vrijling, J. K. Vrouwenvelder, A. C. W. M, 2008. Methods for the estimation of loss of life due to floods: a literature review and a proposal for a new method

IH Cantabria. 2011. Evaluación del riesgo de tsunamis en la costa de El Salvador (Fase I: Peligrosidad). Memoria

IH Cantabria. 2011. Propuesta metodológica para la evaluación del riesgo frente a tsunamis en la costa de El Salvador (Fase II. Vulnerabilidad)

IH Cantabria. 2011. Propuesta metodológica para el cálculo de Indicadores de Vulnerabilidad frente a tsunamis en la costa de El Salvador

ISO 31010. 2009. Risk management -- Risk assessment techniques

Olabarrieta M., Medina R., González M., Otero L., C3: A finite volume-finite difference hybrid model for tsunami propagation and runup, - Computers \& Geosciences, In Press

Okada M, 1985. Surface deformation due to shear and tensile faults in a half-space. Bull. Seism. Soc. Am., 75(4):1135-1154,

P. L.-F. Liu, S-B. Woo, and Y-S Cho. Computer programs for tsunami propagation and inundation. Technical report, Cornell University, 1998

Schneiderbauer, Ehrlich. 2004. Risk, hazard and people's vulnerability to natural hazards. A review of definitions, concepts and data. European Commission. Joint Research Centre. Luxemburg. ISBN 92-894-8732-1.

Synolakis C. E., 1987: The Runup of Solitary Waves. J. Fluid Mechanics, 185, 523-545.

Tyndall Centre for Climate Change Research (2003). Vulnerability, risk and adaptation: A conceptual framework. Working Paper 38.

UNESCO. 2009. Hazard Awareness and Risk Mitigation in Integrated Coastal Management (ICAM). Intergovernmental Oceanographic Commission. IOC Manual and Guides No. 50, ICAM Dossier No. 5, Paris,

UNISDR, 2004. Living with Risk: a Global Review of Disaster Reduction Initiatives, International Strategy for Disaster Reduction, Geneva, UN Publications.

UNISDR, 2009a. UN International Strategy for Disaster Reduction Sec, 15 January 2009. Brussels, 21.12.2010

UNISDR 2009b. Terminology on Disaster Risk Reduction. Published by the United Nations International Strategy for Disaster Reduction (UNISDR). Geneva, Switzerland, May 2009.

Walker, Holling, Carpenter, and Kinzig. 2004. Resilience, adaptability and transformability in socialecological systems. Ecology and Society 9(2): 5.

Wang X., Liu P. L.-F, 2006. COMCOT user manual. Technical report, Cornell University. 